\title{
With Regard to L2 ACAdemic Writing: The Use of Topicalisers in L1 (ENGlish and Spanish) and L2 (English) Research Articles
}

\begin{abstract}
A great deal of cross-cultural research has shown remarkable differences between the written discursive practices of academic disciplinary members using English for international communication and members using other languages for local communication. Less research has been carried out, however, on the possible transfer of non-native scholars' writing practices from their native language into English when drafting their academic texts for an international audience. It is the aim of this paper to contribute to intercultural rhetoric by taking the latter approach. It will look into the use made of a particular cohesive device, topicalisers (i.e. linguistic signals that writers include in the text to organise the discourse, bringing about, changing or re-taking a topic), in Business Management research articles written in L1 (English and Spanish) and L2 (English) research articles. The analysis focuses on the frequency, distribution and choice of topicalisers. Results reveal significant differences in the use of topicalisers in L1 and L2 English research articles, which gives way to a different discourse flow and organisation of information. In the light of the results obtained, the different use of topicalisers made in L2 English texts could be interpreted as a discursive transfer of Spanish scholars' writing conventions in their L1. ${ }^{1}$
\end{abstract}

Key words

Academic writing; English for Academic Purposes (EAP); intercultural rhetoric; research articles; textual markers

\section{Introduction}

English has now become the language of scholarly publication. English publications - most notably, research articles (RAs) - enable scholars to make their 
research available to a large audience and, what is also very relevant, they enable scholars to establish their credentials, get promotions, and, overall, be considered successful academics. This predominance and relevance of English is more marked in certain areas of knowledge, especially hard sciences, medical sciences and also certain social sciences.

The increasing use of English in the academia has triggered a great deal of intercultural research in the academic genre par excellence. Thus, a lot of research has focused on the comparison between RAs written and published in English and RAs written and published in a different L1: Bulgarian (e.g. Vassileva 1997, 1998), German (e.g. Kreutz and Harres 1997), French and Norwegian (e.g. Fløttum et al. 2006; Vold 2006), French (e.g. Carter-Thomas 2007), Italian (e.g. Molino 2010), Czech (e.g. Čmejrková 1996, 2007; Chamonikolasová 2005), Serbian (e.g. Blagojević 2009), and Spanish (e.g. Salager-Meyer et al. 2003; Mur-Dueñas 2007, 2010; Lafuente-Millán et al. 2010). This research has emphasised significant differences in the overall structure of academic articles (Čmejrková 1996, 2007; Chamonikolasová 2005) and in the use of certain rhetorical features in the same genre in each of the languages: hedges and epistemic markers (e.g. Kreutz and Harres 1997; Vassileva 1997, Salager Meyer et al. 2003; Vold 2006), personal pronouns (e.g. Vassileva 1998; Fløttum et al. 2006; Mur-Dueñas 2007; Molino 2010), conditional sentences (e.g. Carter-Thomas 2007) or attitude markers (e.g. Mur-Dueñas 2010). Overall, these studies reveal that the socio-cultural context influences the expression of new academic knowledge in published articles; that is, the particular linguistic and cultural context in which the RAs are written in one and the other language - which in most cases entails a different context, and therefore, audience - is to be seen as a determining factor in the expression of new scientific knowledge.

Less research has been carried out on the analysis of the possible influence of the broader cultural context and the possible transfer of writing conventions from L1 to L2 scholarly publications. Some of these studies are those by Vassileva (2001), Burgess (2002), Shaw (2003), Martínez (2005) and Pérez-Llantada (2010). The results reported regarding the role of the linguistic cultural context in L2 English RA writing vary. On the one hand, Vassileva (2001) does not find any transfer in the use of hedges and boosters in Bulgarian English RAs in linguistics; what she finds is a scarcer use of these features in Bulgarian English than in English and even than in Bulgarian texts. Burgess (2002) concludes that language plays a less determining role than the relationship between the writer and the discourse community in the rhetorical structure of English language and Hispanic studies RAs. On the other hand, Shaw (2003) reports differences in evaluation and promotion traces in applied economics RAs in English, in Danish and in Danish English. As he concludes (2003: 353), when writing in English the Danes use certain features which are "carried over from their 'home' rhetorical environment". A similar conclusion is drawn by Pérez-Llantada (2010) in her analysis of epistemic lexical verbs in biomedical RAs in English, in Spanish and in Spanish English. Her results indicate similar trends in the use of these markers in the two sub-corpora of English texts, 
which points to the fact that international publications call for certain homogeneity and strong deviations from the established conventions may not be allowed. Nevertheless, it seems that certain uses of the interactive features analysed which are favoured in Spanish texts can be traced in their published articles in English. Finally, Martínez's (2005) results point at the underuse of first person pronouns in biomedical RAs written by Spanish scholars in English in comparison to RAs written by native scholars. However, no data are provided on equivalent Spanish texts, so it cannot be fully determined whether there has been linguistic transfer. Nevertheless, other research has found a lower use of these personal markers in Spanish RAs in another discipline, Business Management, (Mur-Dueñas 2007), which may lead to the conclusion that when Spanish scholars draft their texts in English they bring with them certain rhetorical conventions in the use of selfmentions which condition their writing in English. But further cross-cultural L1 (Spanish-English) and L2 (English) research would be needed on the use of this particular rhetorical device to support this conclusion.

It is the aim of this paper to contribute to this intercultural research on academic writing by analysing a textual feature, topicalisers, in RAs written in English by American-based scholars and by Spanish scholars and in RAs written in Spanish. The study will focus on the comparison of their frequency, the most common markers used in each sub-corpora and their distribution across the RA moves. The differences and similarities in the use of a particular textual feature in two L1s will, therefore, be determined. Then, by analysing it in L2 English (Spanish) RAs, an insight will be gained into the extent to which its use mirrors that prevailing in international English publications (and is, therefore, adjusted to the international convention), or that prevailing in local Spanish publications (and is, therefore, transferred from the national "home" convention). This text-based contrastive analysis will allow us: to learn more about how information is organised in RAs in the two languages and contexts of publications, to get a deeper understanding of the extent to which textual organisation features are transferred from L1 (Spanish) RAs in a specific discipline to L2 (English) parallel texts, to explore the degree of rhetorical homogeneity required in English publications or, in other words, the extent to which stylistic conventions need to be textually uniform in international academic communication.

Topicalisers are understood as interactive metadiscourse features which have a cohesive, organizational function in the text. They can be defined as those signals that writers or speakers include in their texts to organise the discourse and to focus the readers' attention on a particular topic. Topicalisers are included in a number of metadiscourse taxonomies together with other connective features (e.g. Vande Kopple 1985, 2002), textual markers (e.g. Crismore et al. 1993) or frame markers ${ }^{2}$ (Hyland 2005; Hyland and Tse 2004). Topicalisers are sentenceinitial markers used mainly to bring about related topics, to change the topic or to re-take an already introduced topic (Vande Kopple 2002), as shown in the following examples taken from the corpus: 
(1) With respect to organizations' internal competencies, our findings support the idea that enterprises that have basic complementary competencies may benefit when they adopt advanced environmental management practices. (ENGBM21-D)

(2) As for participation in national R\&D programs, we observe that being a domestic firm increases the probability in technologically intensive industries. (SPENGBM16-R)

(3) En cuanto a la forma de medir las variables, aunque algunas presentaban originariamente más de dos categorías, al final las transformamos todas en dicotómicas o binarias, siendo las distribuciones de frecuencias las que hemos recogido en la tabla 1. (SPBM9-M)

[As regards the way of measuring variables, although some of them originally presented more than two categories, in the end we grouped them into dichotomies or binary pairs, the frequency of distribution being displayed in Table 1.]

\section{Corpus and methodology}

The analysis is based on three sub-corpora of RAs in the field of Business Management published between 2001 and 2006: (1) ENGBM, comprising 24 RAs written in English by Anglo-American scholars and published in international high-impact journals; (2) SPENGBM, comprising 24 RAs written in English by Spanish scholars and published in international high-impact journals; and (3) SPBM, comprising 24 RAs written in Spanish by Spanish scholars published in local journals.

Table 1. Description of the corpus

\begin{tabular}{|l|c|c|c|c|}
\hline & ENGBM & SPENGBM & SPBM & TOTAL \\
\hline No. of texts & 24 & 24 & 24 & 72 \\
\hline No. of words & 171,447 & 193,025 & 152,154 & 516,626 \\
\hline
\end{tabular}

These sub-corpora form part of a broader corpus, SERAC 1.0 (Spanish-English Research Article Corpus), which contains a total of 576 RAs in 8 disciplines, 72 RAs per discipline divided into ENG, SPENG and SP RAs to enable intercultural as well as interdisciplinary analyses (for further details see Pérez-Llantada 2008).

The selection of high impact journals from which to extract the articles was carried out with the help of some specialists who pointed out the most prestigious and commonly read publications in the field. As a result, three journals were chosen (Academy of Management Journal, Journal of Management and Strategic Management Journal); 8 RAs authored by scholars based at North American universities - which were the great majority in these publications - were randomly 
selected from the most recent to the least recent issues of those journals. In order to compile the SPENGBM sub-corpus, RAs published by Spanish-based scholars in these three top-journals were searched for. None were found in Academy of Management Journal or Journal of Management; 5 were found in Strategic Management Journal. To continue compiling the corpus other international relevant publications in the field were consulted. Spanish Business Management scholars were found to publish some articles in English in the following international journals: British Management Journal, Journal of Management Studies, Omega-International Journal of Management Science, Organization Studies and Research Policy. The Spanish authors of these articles were then contacted to enquire on the process of their writing. More specifically, they were asked whether they had originally written the texts in English or whether they had had them translated by a professional. Those which had been translated were left out, as it is the language of the non-native scholars that we aimed at analysing. Some Spanish scholars mentioned that their RAs had been subject to light linguistic revision following suggestions, recommendations or corrections from referees and editors; in these cases, their final products were incorporated into the corpus. Finally, 3 recognised journals in Spanish were also pointed out by some specialists (Cuadernos de Economía y Dirección de la Empresa, Dirección y Organización de Empresas and Revista Europea de Dirección y Economía de la Empresa); 8 articles from each of the journals were further randomly selected.

In order to carry out the frequency analysis the RAs were carefully read and scanned in search of potential topicalisers in each of the three sub-corpora. This corpus-driven approach was deemed necessary since, although some metadiscourse analyses of English texts include topicalisers and some common types are reported, the array was not exhaustive enough; and in the case of the Spanish texts no such lists were found. The manual search of markers allowed me to spot markers, especially in the L2 RAs, which had not been considered in previous metadiscourse analyses but which are intended to perform the same function. Only initial-sentence markers, whose function is to bring (new) topics into the argument, were considered. Some tokens of the markers which qualified as topicalisers were disregarded when they did not perform the particular textual function mentioned above. Examples 4 to 6 illustrate some of the disregarded tokens in each sub-corpus.

(4) We would expect, therefore, that the lack of a finding regarding relatedness in prior studies might reflect the influence of prior negotiations. (ENGBM2-I)

(5) Secondly, we develop the theoretical background; thirdly, we describe the research design, and show the results; and finally, we conclude with our thoughts with respect to the findings. (SPENGBM5-I)

(6) Su contenido se puede resumir en dos grupos de cuestiones: 1) preguntas encaminadas a determinar el perfil de la empresa en cuanto a tamaño, procesos, productos y mercados, y 2) cuestiones referidas a los tres tipos de 
tecnologías considerados, a fin de determinar si éstas estaban o no en uso. (SPBM24-M)

[Its content can be summarised in two issues: 1) questions intended to determine the profile of the firm as regards size, processes, products and markets, and 2) aspects related to the three types of technologies considered, to determine whether they were or not being used.]

The quantitative analysis was conducted taking into account the different size of the sub-corpora. Furthermore, a chi-square statistical analysis (Preacher 2001) was performed to determine the significance of the differences found. In the reporting of results in the next section statistical values are shown. The significance level was established at $<0.05$.

\section{Results}

As shown in Table 2 below, English RAs written by Spanish scholars present a higher number of topicalisers than English RAs written by American-based scholars. This means that Spanish scholars resort to this cohesive device to bring (new) topics into the argumentation to a greater extent than their American-based international colleagues in similar publications. The different extent of use of topicalisers brings about a somewhat different discourse flow in the two English corpora. Whereas the cumulative unfolding of information illustrated in the examples below is to be found at some point in most L2 English and L1 Spanish Business Management RAs, it is rather uncommon in the English L1 RAs in the corpus.

(7) With regard to the results of LBIO indicator implementation, we recognize that we cannot be sure of having identified all the new products launched from 1997 to 1999 in the analysed industry.

[...] Furthermore, concerning the LBIO implementation, we avoided the problem of variations between industries on the propensity of sending new products announcements to trade and technical journals. (SPENGBM15-D)

(8) Large companies tend to have more financial and human resources to devote to new initiatives and can benefit from scale economies. With respect to internationalization, no significant coefficients are found. This seems to indicate that integration into multinational corporations provides neither advantages nor additional pressures to initiate the ISO14001 certification process.

As for the role of motivational variables, Figure 1 shows a graphical representation of the parameters that facilitate the appreciation of tendencies. As pointed out in Table 4, [...]. (SPENGBM3-R)

(9) En cuanto a los atributos funcionales del producto, se planteó un factor compuesto por las variables promedio "comodidad", "seguridad" y "dura- 
ción". Por lo que se refiere a los atributos de la marca, se especificaron mediante un factor definido por dos variables las cuales son promedio de las dimensiones correspondientes a la utilidad funcional (garantía) y a la utilidad simbólica de la marca (identificación social, estatus e identificación personal). Por último, respecto al precio máximo a pagar por la marca se representó mediante una variable observable que recoge la opinión del encuestado. (SPBM17-R)

[As regards the functional attributes of the product, a factor was established consisting of the average variables "comfort", "security" and "length". As far as the brand attributes are concerned, they were specified by means of a factor defined by two variables, which are the average of the dimensions corresponding to functional utility (guarantee) and brand symbolic utility (social identification, status and personal identification). Finally, with regard to maximum price to pay for the brand, it was represented by an observable variable that gathers the opinions of the person surveyed].

English L1 RAs only rarely thematise the idea to be discussed. The information tends to be organised in such a way that such thematisation is not called upon.

Table 2. Raw and normalised figures of topicalisers in the corpus

\begin{tabular}{|l|c|c|c|}
\hline & ENGBM & SPENGBM & SPBM \\
\hline Raw figures & 26 & 69 & 126 \\
\hline Normalised frequency & 0.2 & 0.4 & 0.8 \\
\hline ENGBM-SPENGBM P-value: $0.000\left(\chi^{2}=19.463 ;\right.$ d.f. $\left.=1\right)$ \\
SPENGBM-SPBM P-value: $0.0000\left(\chi^{2}=17.163\right.$; d.f. $\left.=1\right)$ \\
ENGBM-SPBM P-value: $0.0000\left(\chi^{2}=66.673 ;\right.$ d.f. $\left.=1\right)$
\end{tabular}

The normalised figures in Table 2 further show that the frequency of topicalisers in the Spanish RAs doubles their frequency in the Spanish English RAs (and is four times higher than in the English RAs). As a result, it can be inferred that there is some transfer process in the writing convention of bringing (new) topics of discussion through a sentence-initial marker introducing it. Nevertheless, they are not used to the same extent in the Spanish English RAs, which may point to a possible accommodation process to the conventions prevailing in English RAs.

Not only are the raw and normalized numbers of topicalisers greater in the SPBM and SPENGBM RAs than in the ENGBM ones, but they are also included in a higher percentage of texts. Whereas only 9 L1 English RAs, 21 L2 English RAs and 23 L1 Spanish RAs contain one or more topicalisers. Similarly, the number of topicalisers per RA ranges from 1 to 5 in the ENGBM corpus, from 1 to 8 in the SPENGBM corpus and from 1 to 17 in the SPBM corpus. These data highlight the different writing conventions as regards this particular cohesive device in one and the other linguistic / cultural contexts, and the mid-position that English RAs written by L2 (Spanish) scholars occupy.

The topicalisers that have been found in each of the three sub-corpora, together with the number of tokens of each of them, are shown in Table 3. 
Table 3. Topicalisers in each of the three sub-corpora

\begin{tabular}{|c|c|c|c|c|c|c|c|c|}
\hline & \multicolumn{2}{|c|}{ ENGBM } & & \multicolumn{2}{|c|}{ SPENGBM } & & \multicolumn{2}{|c|}{ SPBM } \\
\hline & Total & $(\%)$ & & Total & $(\%)$ & & Total & $(\%)$ \\
\hline in terms of & 6 & 23.1 & with regard to & 13 & 18.8 & en cuanto a & 47 & 37.0 \\
\hline regarding & 5 & 19.2 & with respect to & 12 & 17.4 & respecto a & 41 & 32.3 \\
\hline with respect to & 5 & 19.2 & regarding & 10 & 14.5 & con respecto a & 12 & 9.4 \\
\hline with regard to & 4 & 15.4 & as for & 9 & 13.0 & en relación a & 8 & 6.3 \\
\hline concerning & 2 & 7.7 & in relation to & 7 & 10.1 & por lo que & 5 & 3.9 \\
\hline considering & 1 & 3.8 & concerning & 6 & 8.7 & respecta a & & \\
\hline in regards to & 1 & 3.8 & with reference to & 5 & 7.2 & en relación con & 4 & 3.1 \\
\hline in relation to & 1 & 3.8 & in terms of & 4 & 5.8 & por lo que se & 4 & 3.1 \\
\hline related to & 1 & 3.8 & as regards & 2 & 2.9 & refiere a & & \\
\hline & & & about & 1 & 1.4 & relacionado con & 2 & 1.6 \\
\hline & & & & & & en lo & 1 & 0.8 \\
\hline TOTAL & 26 & & TOTAL & 69 & & concerniente con & & \\
\hline & & & & & & $\begin{array}{l}\text { en lo que } \\
\text { respecta a }\end{array}$ & 1 & 0.8 \\
\hline & & & & & & $\begin{array}{l}\text { en lo que se } \\
\text { refiere a }\end{array}$ & 1 & 0.8 \\
\hline & & & & & & TOTAL & 126 & \\
\hline
\end{tabular}

Some topicalisers stand out as preferred in each of the three sub-corpora. It is interesting to note that the most common topicalisers do not coincide in the two sub-corpora of English texts. In terms of appears to be not only the most frequent topicaliser in the ENGBM corpus, but also the one used in a wider number of texts (5). Regarding and with respect to also account for a high percentage in the ENGBM corpus and are present in 4 and 3 texts respectively. In the SPENGBM in terms of does not feature as a common topicaliser; the number of tokens of regarding and with respect to represent similar percentages to those in the ENGBM, but with regard to is the most frequent topicaliser and the one used in a higher number of texts (7). In addition, there are some markers which are found in the L2 English texts which are not included in the English texts: as for, with reference to, as regards, and about. The use of these topicalisers can be the result of an attempt to translate some Spanish markers into English and/or the inclusion of markers which tend to be associated with other genres or registers. In the SPBM RAs there seems to be a clear preference for two topicalisers: en cuanto a (47 tokens) and respecto $a$ (41 tokens). They account for almost $70 \%$ of the overall use and at least one token of each topicaliser is found in 14 RAs.

Finally, significant distributional differences arise in the use of these textual features across the two English sub-corpora. Topicalisers are distributed differently across the 4 moves of the English RAs written by Spanish scholars and those written by American-based scholars. On the other hand, the distribution of topicalisers across the RAs written in English and in Spanish by Spanish scholars is rather similar, as shown in Table 4. 
Table 4. Distribution of topicalisers across the 4 moves

\begin{tabular}{|l|ll|ll|lr|}
\hline & \multicolumn{2}{|c|}{ ENGBM } & \multicolumn{2}{c|}{ SPENGBM } & \multicolumn{2}{c|}{ SPBM } \\
& Total & $\mathbf{( \% )}$ & Total & $\mathbf{( \% )}$ & Total & $(\mathbf{\%})$ \\
\hline Introduction & 10 & 38.5 & 11 & 15.9 & 32 & 25.4 \\
\hline Methods & 1 & 3.8 & 17 & 24.6 & 29 & 23.0 \\
\hline Results & 5 & 19.2 & 30 & 43.5 & 54 & 42.9 \\
\hline Discussion & 10 & 38.5 & 11 & 15.9 & 11 & 8.7 \\
\hline & \multicolumn{7}{|l}{ ENGBM-SPENGBM P-value: $0.001\left(\chi^{2}=15.987 ;\right.$ d.f $\left.=3\right)$} \\
& \multicolumn{7}{|l}{ SPENGBM-SPBM P-value: $0.2706\left(\chi^{2}=3.916 ;\right.$ d.f. $\left.=3\right)$} \\
& ENGBM-SPBM P-value: $0.0000\left(\chi^{2}=22.233 ;\right.$ d.f. $\left.=3\right)$
\end{tabular}

The highest number of topicalisers is included in the Results section both in the L2 English and in the L1 Spanish texts. In contrast, topicalisers are mostly used at the beginning and at the end of the L1 English RAs, that is, in the Introductory and the Discussion sections. As a result of these distributional differences, it is in the Results sections that the divergent discourse flow between ENGBM and SPENGBM texts becomes more apparent. At this stage, Spanish scholars tend to present results one after another frequently introduced by means of a topicaliser in thematic position (as in Examples 8 and 9 above), and usually following the order of the information included in the tables and/or the information regarding the variables and types of analyses conducted, which are reported in the Methods section.

A similar presentation of topics or themes occurs in the Methods sections of SPENGBM and SPBM RAs, as shown in the examples below. Example 11 is an extreme case in which 7 subsequent paragraphs start with a topicaliser.

(10) As for the situation of each company with respect to the ISO14001 certification, each respondent was asked to choose one of the following stages: (1) certification not considered, (2) certification considered for the near future, (3) certification in process, and (4) certification awarded. [...]

[...]. With respect to internationalization, $62.5 \%$ of the companies in the sample are integrated into multinational groups. [...]

As for the relationship between motivational and control variables, Table 2 reveals that ethical and relational motivations reach the lowest levels in the electronic equipment industry and the highest in the chemical industry. (SPENGBM3-M)

(11) Respecto al conocimiento de las organizaciones de apoyo del sector de los azulejos, las personas que formaban parte de las entrevistas en profundidad y de las dinámicas de grupo, expresaron de manera espontánea que [...]. En cuanto al conocimiento de los servicios ofrecidos por estas organizaciones, éste es bajo. Respecto a la importancia de los servicios ofrecidos, se considera que estos deben ser importantes para el sector, ya que [...]. En relación con la imagen únicamente las dos instituciones más conocidas son las que muestran una mejor imagen. Además, se manifiesta que [...]. 
Respecto a la investigación cuantitativa, el universo de medida son todas aquellas empresas del sector cerámico en España, que puedan recibir el apoyo de las organizaciones e instituciones objeto de análisis. [...]

Respecto al trabajo de campo, éste fue llevado a cabo por una empresa especializada en este tipo de estudios, por entrevistadores debidamente formados, durante los meses de diciembre de 2000 y enero de 2001.

En cuanto a las variables analizadas en el estudio y a la medición de las mismas, como se desprende de las hipótesis planteadas, las variables objeto de análisis son: [...] (SPBM11-M)

[With respect to the knowledge about the organizations which support the tile sector, those who were interviewed in detail and participated in the peer groups, spontaneously expressed that [...].

As regards the knowledge of the services offered by these organizations, it is low.

With respect to the importance of the services offered, it is considered that they must be important to the sector, since [...].

Regarding image only the two best known institutions are the ones which show a better image. In addition, it is stated that [...].

As regards the quantitative research, the sample are all the firms in the tile sector in Spain which can get support from the organizations and institutions under analysis.]

Although the percentage of topicalisers in the Methods and Results sections of RAs written by Spanish scholars in English and in Spanish is similar, the overall frequency of markers in the Results sections of Spanish RAs is remarkably higher than that in the same sections of the L2 English RAs. Therefore, Spanish scholars seem to partially transfer their writing conventions in their L1 in the use of the textual markers under analysis, but at the same time they seem to (consciously or unconsciously) refrain from accruing too many of these markers in their L2 RAs.

\section{Discussion}

This paper has aimed at contributing to the literature on Intercultural Rhetoric within English for Academic Purposes through the contrastive analysis of topicalisers in RAs in a single discipline written in L1 English and Spanish and L2 English. The corpus-based analysis has revealed significant differences in the frequency of use, particular choice of markers, and distribution of these textual markers between the RAs in English written by American-based scholars and the RAs in English and in Spanish written by Spanish scholars.

First, the normalised frequency of use of topicalisers in the L2 English texts lies between that of L1 English texts and that of L1 Spanish texts. Spanish RAs contain four times as many topicalisers as L1 English RAs and twice as many as L2 English RAs. It has been argued that the different extent of use of these mark- 
ers brings about a different organization of information and a different discourse flow in the RAs. As has been pointed out, topicalisers are initial-sentence rhetorical devices with the aim of drawing the readers' attention to a particular point, indicating a topic change, an introduction of a related topic and/or a re-elaboration of an already introduced topic. Bearing in mind their particular function, the higher number of these markers in the RAs in Spanish than in the RAs in English may be taken to be a result of the allegedly reader-responsible style (Hinds 1987) of Romance languages or content-oriented cultures (Clyne 1994) such as Spanish. The favoured lengthier, more elaborate arguments of reader-responsible languages may call for a greater number of these markers than writer-responsible style languages, such as English; in the texts written in the latter language, an emphasis seems to be placed on linearity and, as a result, other metadiscourse markers which do not signal the introduction or re-elaboration of a particular point but which rather mark a logical transition or progression of ideas. In this sense, the Spanish Business Management scholars writing their RAs in L2 English seem to retain some of the stylistic preferences in parallel written Spanish texts.

Second, differences have also been reported on the most frequent realizations of topicalisers in the two English sub-corpora. The most frequent topicalisers do not coincide, and there are some markers in the RAs written in English by Spanish scholars which are not found at all in the RAs written in English by American-based scholars.

Finally, the distribution of topicalisers is significantly different across the four moves of the L1 and L2 English RAs and rather similar across the four moves of the Spanish and L2 English RAs. Whereas in the L1 English RAs the highest percentages of topicalisers are found in the Introduction and Discussion sections, in the L1 Spanish and L2 English RAs topicalisers tend to be more prominent in the Results and Methods sections. It is, therefore, in the presentation of the results and in the description of the sample, variables and methodological procedures that the above mentioned differences in the information structure and discourse flow emerge.

Overall, the results reported are in line with those by Shaw (2003) and PérezLlantada (2010) in that they show that L2 scholars writing their RAs in English for an international readership bring with them some rhetorical conventions which are transferred from their L1 writing, but only up to a point. The prevalent rhetorical conventions in international publications also impinge on there L2 English writing, regardless of whether that is the result of proofreading and reviewing processes that their texts have gone through or of their (un)conscious accommodation to rhetorical preferences in English medium international publications, as they are constantly exposed to these sources through reading (and perhaps tuition). As Shaw (2003: 355) puts it, "[t]hey probably internalise a good deal of their rhetoric from international publications in English, and are ultimately subject to sanctions by international editors if they depart too far from the expected norms". According to the results, the English L2 RAs may seem to reach a compromise between the conventions prevailing in parallel texts in the schol- 
ars' native language, and which tend to be carried over, and the conventions prevailing in international publications in English, so that they do not depart too far from the expected norms. As a result, even though there seems to be some space for traces of divergent discourse conventions favoured in the national language and context, international RAs in English - whether written by L1 or L2 scholars - present a high degree of homogeneity, which, as Pérez-Llantada (2010) states, can be a result of the globalisation process which may also be affecting the writing practices of the academia.

To conclude, this study presents some limitations which could be overcome by future research. First, the analysis was based on just a cohesive marker; it could be expanded to cover other markers whose use has been reported to be different in the two languages and contexts (i.e. Spanish/national vs. English/international) in the literature to explore to what extent Spanish scholars writing in English also transfer their writing conventions as regards their use and/or accommodate to the writing conventions favoured in international publications. This would allow drawing conclusions as to whether Spanish academics are (not) fully aware of other organizational and cohesive mechanisms in English RAs. Also, parallel analyses could be undertaken based on texts in other languages to examine to what extent similar transfer/accommodation processes are at stake in other L1 scholars writing RAs in L2 English. In addition, the corpus consisted of RAs in a single discipline. Further parallel analyses could determine whether a similar process takes place in other disciplinary contexts. Finally, although the different use of this textual feature by Spanish scholars when writing their RAs in English has not prevented publication in an international journal, it would be interesting to explore whether the use of certain textual patterns may influence the chances of being read and cited by other international colleagues. It may be the case that deviations from the conventional organization of information and discourse flow in international publications may affect the number of scholars who actually read and cite their RAs after reaching publication. In a similar vein, taking a combined corpus-based and ethnographic approach, the extent to which these deviations are referred to by referees and can be potential causes for rejection or major revision decisions in a review process could also be further explored.

\section{Notes}

1 I am indebted to the local and national educational authorities, the Diputación General de Aragón and the Ministerio de Ciencia e Innovación (MICIIN), for funding the research group InterLAE (H21) and the research project "La integridad genérica en la comunicación académica y profesional: los géneros y su correlación con las prácticas discursivas y con la cultura de distintas comunidades profesionales (FFI2009-09792)", respectively. term "topicaliser", used by Williams (1981) and adopted by most metadiscourse analysts (Crismore et al. 1993; Vande Kopple 1985, 2002), is preferred in this study, as it is believed that topicalisers do not necessarily shift the topic of the argumentation but sometimes retake a previously discussed topic, as can be seen in the examples provided. 


\section{References}

Blagojević, Savka (2009) 'Expressing attitudes in academic research articles written by English and Serbian authors'. Facta Universitatis. Linguistics and Literature 7(1), 63-73.

Burgess, Sally (2002) 'Packed houses and intimate gatherings: Audience and rhetorical strategies'. In: Flowerdew, John (ed.) Academic Discourse. London: Longman, 196-225.

Carter-Thomas, Shirley (2007) 'The "iffiness" of medical research articles: A comparison of English if and French si'. In: Fløttum, Kjersti (ed.) Language and Discipline Perspectives on Academic Discourse. Newcastle: Cambridge Scholars Press, 161-187.

Chamonikolasová, Jana (2005) 'Comparing the structures of texts written in English and Czech'. In: Slovak Studies in English I Conference Proceedings, 77-84. Bratislava: Univerzita Komenského.

Clyne, Michael (1994) 'Cultural differences in the organization of academic texts'. Journal of Pragmatics 11, 211-247.

Čmejrková, Světla (1996) 'Academic writing in Czech and English’. In: Ventola, Eija and Anna Mauranen (eds.) Academic Writing: Introduction and Textual Issues. Amsterdam and Philadelphia: John Benjamins, 137-145.

Čmejrková, Světla (2007) 'Intercultural dialogue and academic discourse'. In Grein, Marion and Edda Weigand (eds.) Dialogue and Culture. Amsterdam and Philadelphia: John Benjamins, 73-94.

Crismore, Avon, Raija Markkanen and Margaret S. Steffensen (1993) 'Metadiscourse in persuasive writing: A study of texts written by American and Finnish University students'. Written Communication 10(1), 39-71.

Fløttum, Kjersti, Trine Dahl and Trodd Kinn (2006) Academic Voices - Across Languages and Disciplines. Amsterdam and Philadelphia: John Benjamins.

Kreutz, Heinz and Annette Harres (1997) 'Hedging in German and English academic writing'. In: Duszak, Anna (ed.) Culture and Styles of Academic Discourse. Berlin and New York: Mouton de Gruyter, 181-201.

Hinds, John (1987) 'Reader versus writer responsibility: A new typology'. In: Connor, Ulla and Robert B. Kaplan (eds.) Writing across Languages. Analyses of L2 Texts. Reading: AddisonWeslye, 141-152.

Hyland, Ken (2005) Metadiscourse. London: Continuum.

Hyland, Ken and Polly Tse (2004) 'Metadiscourse in academic writing: A reappraisal'. Applied Linguistics 25(2), 156-177.

Lafuente-Millán, Enrique, Pilar Mur-Dueñas, Rosa Lorés-Sanz and Ignacio Vázquez-Orta (2010) 'Interpersonality in written academic discourse: three analytical perspectives'. In Lorés-Sanz, Rosa, Pilar Mur-Dueñas and Enrique Lafuente-Millán (eds.) Constructing Interpersonality: Multiple Perspectives on Written Academic Discourse. Newcastle: Cambridge Scholars Publishing, 13-39.

Martinez, Iliana (2005) 'Native and non-native writer's use of first person pronouns in the different sections of biology research articles in biology'. Journal of Second Language Writing 14, 174-190.

Molino, Alessandra (2010) 'Personal and impersonal authorial references: A contrastive study of English and Italian linguistics research articles'. Journal of English for Academic Purposes 9(2), 86-101.

Mur-Dueñas, Pilar (2007) “"I/we focus on...”: A cross-cultural analysis of self-mentions in business management research articles'. Journal of English for Academic Purposes 6(2), 143-162.

Mur-Dueñas, Pilar (2010) 'Attitude markers in business management research articles: A crosscultural corpus-driven approach'. International Journal of Applied Linguistics 19, 50-72.

Pérez-Llantada, Carmen (2008) 'Humans vs. machines? A multiperspective model for ESP discourse analysis in intercultural rhetoric research'. ESP Across Cultures 5, 91-104.

Pérez-Llantada, Carmen (2010) 'Researching into English for research publication purposes from an applied intercultural perspective'. In Ruiz-Garrido, Miguel F., Juan Carlos Palmer-Silveira 
and Inmaculada Fortanet-Gómez (eds.) English for Professional and Academic Purposes. Amsterdam: Rodopi, 25-41.

Preacher, K. J. (2001) 'Calculation for the chi-square test: an interactive calculation tool for chisquare tests of goodness of fit and independence'. [Computer software]. Available from http:// www.people.ku.edu/ preacher/chisq/chisq.htm

Salager-Meyer, Françoise, María Angeles Alcaraz Ariza and Nahirana Zambrano (2003) 'The scimitar, the dagger and the glove: Intercultural differences in the rhetoric of criticism in Spanish, French and English medical discourse (1930-1995)'. English for Specific Purposes 22, 223-247.

Shaw, Philip (2003) 'Evaluation and promotion across languages'. Journal of English for Academic Purposes 2, 343-357.

Vassileva, Irena (1997) 'Hedging in English and Bulgarian academic writing'. In: Duszak, Anna (ed.) Culture and Styles of Academic Discourse. Berlin and New York: Mouton de Gruyter, 203221.

Vassileva, Irena (1998) 'Who am I/Who are we in academic writing?' International Journal of Applied Linguistics 8, 163-190.

Vassileva, Irena (2001) 'Commitment and detachment in English and Bulgarian academic writing'. English for Specific Purposes 20(1), 83-102.

Vande Kopple, William (1985) 'Some exploratory discourse on metadiscourse'. College Composition and Communication 36, 63-94.

Vande Kopple, W. (2002) 'Metadiscourse, discourse and issues in composition and rhetoric'. In Ellen Barton and Gail Stygall (eds.) Discourse Studies in Composition. New Jersey: Hampton Press, 91-113.

Vold, Eva T. (2006) 'Epistemic modality markers in research articles: A cross-linguistic and crossdisciplinary study'. International Journal of Applied Linguistics 16, 61-87.

Williams, Joseph M. (1981) Style: Ten Lessons in Clarity and Grace. Harper Collins Publishers.

Pilar Mur-Dueñas received her PhD in English Studies from the Universidad Zaragoza (Spain), where she is currently a lecturer of the English Department in the Faculty of Education. Her research interests focus on genre analysis, written academic discourse, corpus studies and intercultural rhetoric. The results of her research on the intercultural analysis of interpersonality in research article writing have been published in international journals such as Journal of Pragmatics, International Journal of Applied Linguistics and Journal of English for Academic Purposes. She is a member of the InterLAE research group (www.interlae.com).

Address: Pilar Mur-Dueñas, Departamento de Filología Inglesa y Alemana, Facultad de Educación, Universidad de Zaragoza, C/San Juan Bosco 7, 50009 Zaragoza, Spain. [e-mail: pmur@unizar.es] 